\title{
FAKTOR YANG MEMPENGARUHI MINAT PEMBELIAN PRODUK SECARA ONLINE MENGGUNAKAN FACEBOOK BERDASARKAN TECHNOLOGY ACCEPTANCE MODEL DAN THEORY OF PLANNED BEHAVIOR ( Studi Kasus pada Mahasiswa di Kota Yogyakarta )
}

\author{
Jajuk Herawati \\ Fakultas Ekonomi Universitas Sarjanawiyata Tamansiswa \\ email: jajuk.herawati@yahoo.com
}

\begin{abstract}
ABSTRAK
Penelitian ini bertujuan untuk mengetahui dan menguji pengaruh sikap, normanorma subyektif, kontrol perilaku, dan kegunaan pada minat menggunakan FB untuk pembelian online. Selain itu juga pengaruh kegunaan pada sikap, dan pengaruh kemudahan penggunaan pada sikap. Penelitian dilakukan di kota Yogyakarta pada bulan Juni 2018. Sampel yang digunakan dalam penelitian (yang mengembalikan kuesioner dengan isian lengkap) sebanyak 114 orang mahasiswa, yang diambil secara purposive sampling. Metode analisis data yang digunakan untuk menguji hipotesis penelitian adalah analisis jalur (path analysis). Hasil penelitian ini menunjukkan: (1) Sikap terhadap penggunaan FB berpengaruh positif dan signifikan pada minat menggunakan FB untuk pembelian online; (2) Norma-norma subyektif berpengaruh positif dan signifikan pada minat menggunakan FB untuk pembelian online; (3) Kontrol perilaku berpengaruh positif dan signifikan pada minat menggunakan FB untuk pembelian online; (4) Kegunaan berpengaruh positif dan signifikan pada minat menggunakan FB untuk pembelian online; (5) Kegunaan berpengaruh positif dan signifikan pada Sikap terhadap penggunaan FB; (6) Kemudahan penggunaan berpengaruh positif dan signifikan pada Sikap terhadap penggunaan FB.

Kata kunci: purposive sampling, path analysis.
\end{abstract}

\section{PENDAHULUAN}

Kemajuan teknologi informasi telah berdampak besar bagi kehidupan manusia. Berkat kemajuan teknologi informasi, komunikasi antar manusia dapat dilakukan dengan lebih cepat, dan tidak terkendala oleh tempat dan waktu. Dengan kata lain, kemajuan teknologi informasi telah membuat komunikasi manusia menjadi lebih efisien dan efektif. Salah satu bentuk hasil kemajuan teknologi informasi tersebut adalah jejaring sosial (social networking). Jejaring sosial pada dasarnya merupakan suatu struktur sosial yang terbentuk dari simpulsimpul individu maupun organisasi, yang terjalin dengan satu lebih jenis ikatan spesifik seperti nilai (value), visi, ide, teman, keturunan, pandangan politik, bakat dan lainlain (Jadi, 2009; Madcoms, 2011). 
Salah satu bentuk turunan dari jejaring sosial adalah facebook (FB). FB adalah suatu bentuk layanan jejaring sosial dan micro blogging untuk dapat saling berkomunikasi dengan teman, keluarga, atau rekan bisnis (Priyatno, 2010). Melalui $F B$, pengguna dapat saling tukar informasi, mencari teman, menjalin hubungan, atau melakukan kegiatan promosi suatu produk atau jasa agar diketahui dan diminati oleh banyak orang. Berdasarkan hasil perhitungan tahun 2018 oleh Semiocast, peneliti sosial media, ada lima negara yang dianggap paling banyak menggunakan FB. Negara terbanyak pertama adalah Amerika Serikat, kedua Jepang, ketiga Indonesia, keempat Inggris, dan kelima Brazil. Sebanyak 24,3 persen pengguna di Amerika Serikat, Jepang menyumbang 9,3 persen pengguna. Sementara Indonesia memberikan angka sebanyak 6,5 persen pengguna (www.tempo.com).

Bagi pelaku bisnis online baik perusahaan maupun perorangan, banyaknya pengguna FB di Indonesia tersebut telah menjadi peluang untuk melakukan kegiatan pemasarannya. Hal ini tampak dari dimilikinya FB oleh hampir semua perusahaan besar maupun menengah, bahkan perusahaan kecil di Indonesia. Hal ini memberikan implikasi bahwa peluang penggunaan FB khususnya untuk tujuan pembelian atau bisnis online masih besar.

Pertanyaan mendasar dan penting untuk diketahui jawabannya khususnya bagi pelaku bisnis online adalah, faktor-faktor apa saja yang mendorong, mempengaruhi atau menentukan orang menggunakan FB untuk melakukan pembelian produk secara online. Jika faktor-faktor tersebut diketahui, maka upayaupaya peningkatan minat masyarakat menggunakan FB dapat dilakukan secara efektif dan efisien. Selanjutnya, jika minat menggunakan FB dapat ditingkatkan maka perilaku penggunaan $F B$ diharapkan juga meningkat.

\section{Menurut Technology}

Acceptance Model (TAM) yang dikembangkan oleh Davis (1989 dalam Nasri dan Charfeddine, 2012), minat (intention) seseorang untuk menggunakan atau mengadopsi suatu teknologi dipengaruhi oleh sikap (attidude) terhadap teknologi tersebut dan kegunaan yang dipersepsikan (perceived usefulness). Sikap itu sendiri dipengaruhi oleh kegunaan yang dipersepsikan (perceived usefulness) dan kemudahaan penggunaan (perceived ease of use). Menurut Nasri dan Charfeddine (2012) Technology Acceptance Model (TAM) banyak digunakan oleh peneliti di bidang teknologi informasi dan sistem informasi untuk memprediksi perilaku penerimaan teknologi.

Selain TAM, salah satu teori yang berkaitan dengan perilaku yang sering dipakai dalam penelitian di bidang teknologi informasi dan sistem informasi adalah Theory of Planned Behavior (TPB), yang dikembangkan olah Ajzen (1985 dalam Peterson, 2012). Menurut TPB minat merupakan prediktor yang penting dari perilaku, di mana minat ditentukan oleh sikap terhadap perilaku yang akan dilakukan, norma-norma subyektif (subjective norms) yang berhubungan dengan perilaku yang akan dilakukan, dan kontrol perilaku (perceived 
behavioral control) untuk melakukan perilaku tersebut.

Dalam penelitian ini, peneliti menggunakan gabungan dari kedua teori tersebut yaitu TAM dan TPB untuk menguji pengaruh variabelvariabel yang diduga mempengaruhi minat mengadopsi atau menggunakan $F B$ untuk tujuan pembelian produk secara online.

\section{TINJAUAN PUSTAKA}

\section{Theory of Planned Behavior (TPB)}

Theory of Planned Behavior (TPB) merupakan salah satu teori tentang perilaku manusia yang paling sering digunakan dalam penelitian-penelitian perilaku. Teori ini dikembangkan oleh Ajzen pada tahun 1985 (Fusilier and Durlabhji, 2005). TPB menjelaskan faktor-faktor penentu perilaku sadar manusia. Menurut teori ini, perilaku (behavior) seseorang ditentukan oleh minatnya untuk berperilaku (behavioral intention). Minat berperilaku ditentukan oleh tiga variabel yaitu sikap terhadap perilaku (attitude toward behavior), norma-norma subyektif (subjective norms), dan kontrol perilaku persepsian (perceived behavioral control).

Hubungan antar variabel yang terdapat dalam TPB dapat digambarkan sebagai berikut: Scannell (2011)

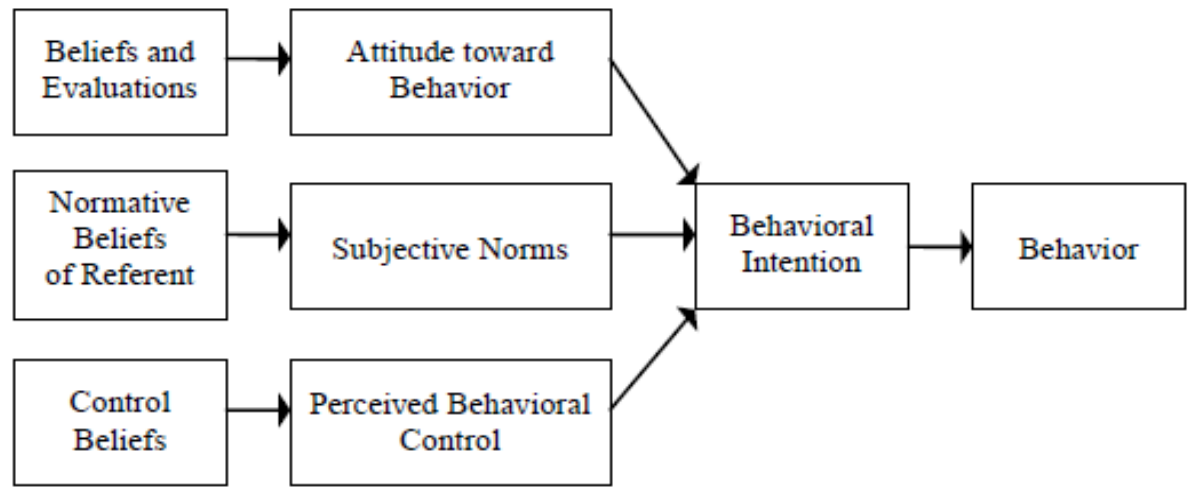

Gambar 2.1. Theory of Planned Behavior

\section{Technology Acceptance Model (TAM)}

Pada awalnya Technology Acceptance Model (TAM) dirancang sebagai model penerimaan teknologi informasi yang akan digunakan oleh pemakai. TAM didasari oleh asumsi bahwa, keputusan yang diambil oleh seseorang untuk menerima suatu teknologi merupakan tindakan sadar yang dapat dijelaskan dan diprediksi minat perilakunya (Jogiyanto, 2007).

Hubungan antar variabelyang terdapat dalam TAM tampak seperti dalam gambar berikut (Sheikhshoaei dan Oloumi, 2011); 


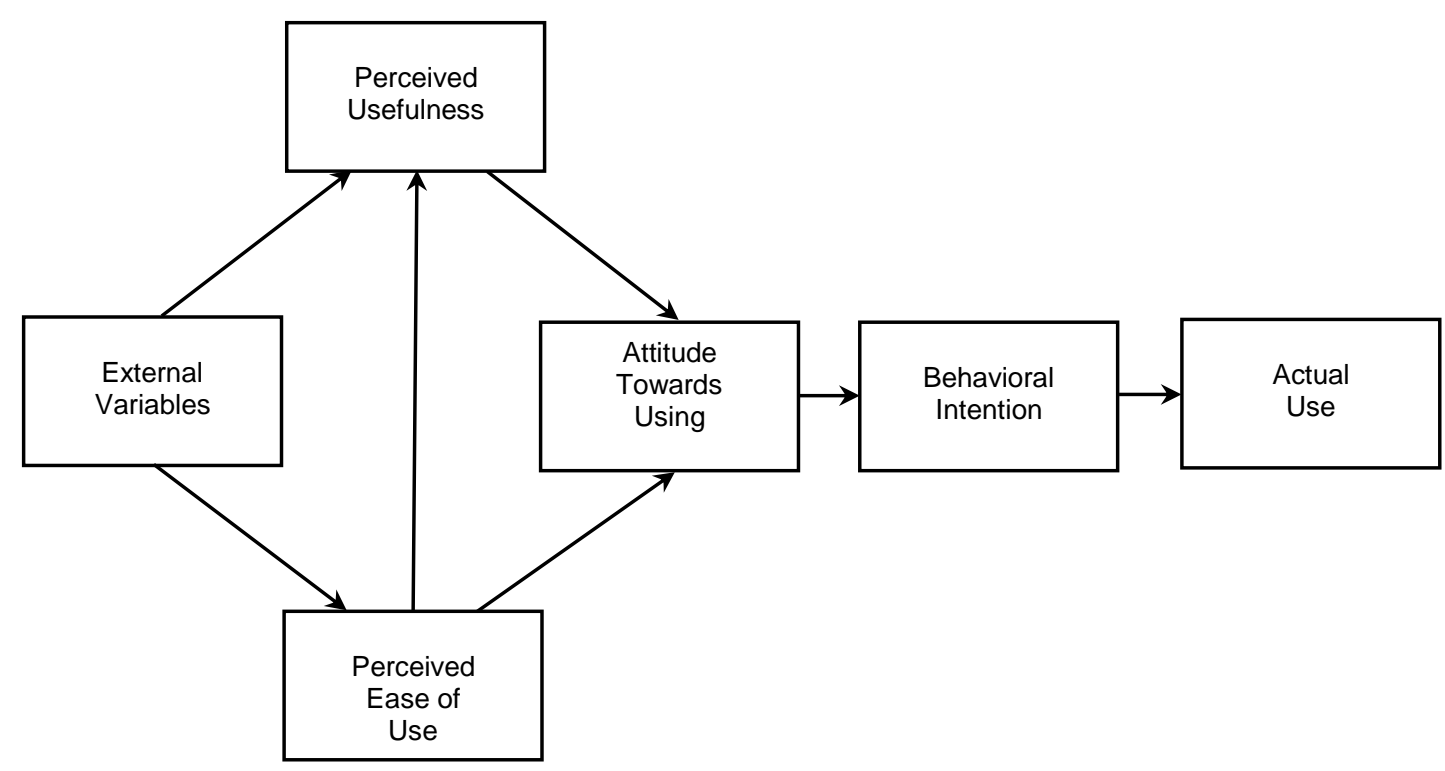

Gambar 2.2. Technology Acceptance Model (TAM)

Menurut TAM sikap terhadap penggunaan ditentukan oleh dua variabel yaitu kemudahan penggunaan persepsian (perceived ease of use) dan kegunaan persepsian (perceived usefulness). Sedangkan faktor eksternal mencakup faktorfaktor sosial dan organisasional (Sheikhshoaei dan Oloumi, 2011).

\section{HIPOTESIS}

Hipotesis yang diajukan dalam penelitian ini sebagai jawaban sementara terhadap rumusan masalah adalah sebagai berikut:

1. Sikap berpengaruh positif pada minat menggunakan FB untuk pembelian online.

2. Norma-norma subyektif berpengaruh positif pada minat menggunakan FB untuk pembelian online.

3. Kontrol perilaku berpengaruh positif pada minat menggunakan FB untuk pembelian online.

4. Kegunaan berpengaruh positif pada minat menggunakan FB untuk pembelian online.
5. Kegunaan berpengaruh positif pada sikap.

6. Kemudahan penggunaan berpengaruh positif pada sikap.

\section{METODE PENELITIAN}

Penelitian ini direncanakan akan dilakukan di kota Yogyakarta. Waktu penelitian ini pada bulan Juni 2018. Populasi dalam penelitian ini adalah mahasiswa di kota Yogyakarta. Pengambilan sampel dalam penelitian ini dilakukan secara purposive sampling, yaitu metode pengambilan atau penentuan sampel dari populasi yang didasarkan pada pertimbangan atau tujuan tertentu (Sugiyono, 2011). Adapun 
pertimbangan yang digunakan dalam pengambil sampel penelitian ini adalah: mahasiswa yang menggunakan FB sebagai media sosial untuk melakukan transaksi belanja online.

Jumlah variabel dalam penelitian ini sebanyak 6 variabel, jika digunakan kelipatan 15 kali, maka jumlah sampel minimal yang diperlukan adalah $15 \times 6=90$ orang. Namun demikian untuk mengantisipasi kuesioner yang tidak kembali, maka peneliti memutuskan untuk menggunakan 100 orang responden.

\section{Definisi Operasional}

Definisi operasional dari masing-masing variabel penelitian ini adalah sebagai berikut:

\section{Kegunaan}

\begin{tabular}{llr}
\multicolumn{2}{c}{ Kegunaan } & \multicolumn{2}{c}{ persepsian } \\
adalah persepsi & \multicolumn{2}{c}{ responden } \\
terhadap daya guna & FB dalam \\
mendukung & kegiatan atau \\
aktivitasnya berbelanja atau
\end{tabular}
melakukan pembelian produk secara online. Pengukuran variabel kegunaan persepsian mengadopsi dari kuesioner yang dikembangkan oleh Amin (2009) dengan indikator sebagai berikut:

1) Penggunaan FB membuat saya leluasa mencari produk yang saya inginkan atau saya butuhkan.

2 Penggunaan FB menghemat waktu dalam berbelanja.

3) Penggunaan FB menghemat tenaga dalam berbelanja.

4) Penggunaan FB membuat transaksi pembelian dapat saya lakukan kapan dan di mana saja.

5) Penggunaan FB untuk berbelanja secara online lebih aman dibanding berbelanja secara konvensional.

\section{Kemudahan Penggunaan}

\begin{tabular}{lrr}
\multicolumn{3}{c}{ Kemudahaan penggunaan } \\
adalah persepsi & responden \\
terhadap mudah & tidaknya \\
menggunakan $\quad$ FB & untuk \\
berbelanja secara & online.
\end{tabular} Pengukuran variabel kemudahan penggunaan persepsian mengadopsi dari kuesioner yang dikembangkan oleh Amin (2009) dengan indikator sebagai berikut:

1) FB mudah digunakan

2) Untuk memahami dan dapat mengoperasikan FB tidak diperlukan waktu yang lama.

3) FB dapat digunakan di mana saja dan kapan saja.

\section{Sikap}

Sikap adalah sikap responden terhadap penggunakan FB untuk melakukan pembelian produk atau belanja. Pengukuran variabel kemudahan penggunaan persepsian mengadopsi dari kuesioner yang dikembangkan oleh Aboelmaged (2010) dengan indikator sebagai berikut:

1) Menggunakan FB untuk melakukan pembelian produk merupakan ide yang baik.

2) Menggunakan FB untuk melakukan pembelian produk merupakan tindakan yang bijaksana.

3) Menggunakan FB untuk melakukan pembelian produk merupakan aktivitas yang menyenangkan.

\section{Norma Subyektif}

Norma subyektif adalah anjuran orang lain yang dianggap penting oleh responden agar 
menggunakan FB untuk melakukan pembelian produk secara online. Pengukuran variabel kemudahan penggunaan persepsian mengadopsi dari kuesioner yang dikembangkan oleh Aboelmaged (2010) dengan indikator sebagai berikut:

1) Orang-orang yang saya anggap penting, menyarankan kepada saya agar menggunakan FB untuk kegiatan pembelian produk.

2) Orang-orang berpengaruh pada diri saya, menyarankan kepada saya agar menggunakan FB untuk kegiatan pembelian produk.

3) Orang-orang sering memberikan pendapat dan saran kepada saya, menyarankan kepada menggunakan FB untuk kegiatan pembelian produk.

\section{Kontrol Perilaku}

Kontrol perilaku adalah persepsi responden terhadap sumber daya serta hambatanhambatan yang mungkin dihadapi dalam menggunakan FB. Pengukuran variabel kemudahan penggunaan persepsian mengadopsi dari kuesioner yang dikembangkan oleh Aboelmaged (2010) dengan indikator sebagai berikut:

1) Saya memiliki pengetahuan untuk menggunakan FB.

2) Saya memiliki kemampuan untuk menggunakan FB.

3) Saya yakin dapat menggunakan FB dengan baik.

\section{Minat Menggunakan FB}

\begin{abstract}
Minat menggunakan FB adalah keinginan responden menggunakan FB untuk melakukan pembelian/belanja produk secara online. Pengukuran variabel kemudahan penggunaan persepsian mengadopsi dari kuesioner yang dikembangkan oleh Aboelmaged (2010) dengan indikator sebagai berikut:

1) Dalam waktu dekat saya akan menggunakan $F B$ untuk melakukan pembelian produk.

2) Saya ingin menggunakan $F B$ untuk mendukung aktivitas pembelian produk.
\end{abstract}

\section{F. Metode Analisis Data}

Metode analisis data yang digunakan dalam penelitian ini adalah metode deskriptif dan metode inferensial.

a. Metode Deskriptif

Metode deskriptif merupakan metode analisis data yang digunakan untuk mendeskripsikan variabel penelitian. Alat analisis yang digunakan dalam analisis deskriptif ini adalah tabel frekuensi, dalam bentuk tabel persentase (\%).

b. Metode Inferensial/Kuantitatif

Metode inferensial adalah metode analisis data inferensial yang digunakan untuk melakukan pengujian hipotesis. Analisis data inferensial yang digunakan dalam penelitian ini adalah analisis jalur (path analysis). Analisis jalur ini pada dasarnya merupakan pengembangan dari analisis regresi; yang digunakan untuk menguji model hubungan sebabakibat (Sugiyono, 2010). 


\section{ANALISIS DATA DAN PEMBAHASAN}

\section{A. Deskripsi Responden}

Penelitian ini awalnya menggunakan 120 orang responden, tetapi dari jumlah tersebut hanya 114 orang yang mengembalikan kuesioner dengan isian lengkap. Oleh karena itu, jumlah responden dalam penelitian ini sebanyak 114 orang. Adapun deskripsi responden penelitian ini adalah sebagai berikut:

\section{Jenis Kelamin}

Deskripsi responden penelitian ini jika ditinjau dari jenis kelaminnya tampak sebagaimana disajikan dalam Tabel 4.1.

Tabel 4.1

Deskripsi Responden

Berdasarkan Jenis Kelamin

\begin{tabular}{lccc}
\hline & \multirow{2}{*}{ Jenis Kelamin } & $\begin{array}{c}\text { Jumlah } \\
\text { (orang) }\end{array}$ & $\begin{array}{c}\text { Persentase } \\
(\%)\end{array}$ \\
\hline Laki-laki & & 81 & 71,05 \\
Perempuan & & 33 & 28,95 \\
\hline & Jumlah & 114 & 100,00 \\
\hline
\end{tabular}

Sumber: Data Primer, 2018 diolah.

Berdasarkan data yang disajikan dalam Tabel 4.1 tampak bahwa, dari 114 orang responden penelitian ini 81 orang $(71,05 \%)$ di antaranya adalah laki-laki; sedangkan 33 orang sisanya $(28,95 \%)$ adalah perempuan. Dengan demikian dapat Tabel 4.2

Deskripsi Responden Berdasarkan Umur

\begin{tabular}{ccc}
\hline $\begin{array}{c}\text { Umur } \\
\text { (tahun) }\end{array}$ & $\begin{array}{c}\text { Jumlah } \\
\text { (orang) }\end{array}$ & $\begin{array}{c}\text { Persentase } \\
(\%)\end{array}$ \\
\hline$<20$ & 13 & 11,40 \\
$20-26$ & 89 & 78,07 \\
$>26$ & 12 & 10,53 \\
\hline Jumlah & 114 & 100,00 \\
\hline \multicolumn{3}{c}{ Berdasarkan data } \\
\multicolumn{3}{c}{ yang disajikan dalam Tabel } \\
4.2 tampak bahwa, dari 114 \\
\multicolumn{3}{c}{ orang }
\end{tabular}

disimpulkan bahwa, sebagian besar responden penelitian ini berjenis kelamin laki-laki.

2. Umur

Deskripsi responden penelitian ini jika ditinjau dari umurnya tampak sebagaimana disajikan dalam Tabel 4.2.

ini 13 orang responden $(11,40 \%)$ berumur kurang dari 20 tahun; 89 orang $(78,07 \%)$ berumur antara 20 26 tahun; dan 12 orang $(10,53 \%)$ berumur lebih dari 26 tahun. Dengan demikian dapat disimpulkan bahwa, sebagian besar responden penelitian ini berumur antara 20-26 tahun.

\section{Lama Menggunakan Facebook}


Deskripsi responden penelitian ini jika ditinjau dari lamanya menggunakan
Facebook

tampak sebagaimana disajikan dalam Tabel 4.3.

Tabel 4.3

Deskripsi Responden

Berdasarkan Lamanya Menggunakan Facebook

\begin{tabular}{ccc}
\hline $\begin{array}{c}\text { Lama Menggunakan FB } \\
\text { (tahun) }\end{array}$ & $\begin{array}{c}\text { Jumlah } \\
\text { (orang) }\end{array}$ & $\begin{array}{c}\text { Persentase } \\
(\%)\end{array}$ \\
\hline$<1$ & 15 & 13,16 \\
$1-3$ & 37 & 32,46 \\
$>3$ & 62 & 54,39 \\
\hline Jumlah & 114 & 100,00 \\
\hline
\end{tabular}

Sumber: Data Primer, 2018 diolah.

Berdasarkan data yang disajikan dalam Tabel 4.3 tampak bahwa, dari 114 orang responden penelitian ini 15 orang responden $(13,16 \%)$ telah menggunakan FB kurang dari 1 tahun; 37 orang $\quad(32,46 \%) \quad$ telah menggunakan FB selama antara 1-3 tahun; dan 62 orang (54,39\%) telah menggunakan FB selama lebih dari 3 tahun. Dengan demikian dapat disimpulkan bahwa sebagian besar responden penelitian telah menggunakan FB lebih dari 3 tahun.

\section{Jenjang Studi}

Deskripsi responden penelitian ini jika ditinjau dari jenjang studinya tampak sebagaimana disajikan dalam Tabel 4.4.

Tabel 4.4

Deskripsi Responden

Berdasarkan Jenjang Studi

\begin{tabular}{ccc}
\hline $\begin{array}{c}\text { Jenjang } \\
\text { Studi }\end{array}$ & $\begin{array}{c}\text { Jumlah } \\
\text { (orang) }\end{array}$ & $\begin{array}{c}\text { Persentase } \\
(\%)\end{array}$ \\
\hline D3 & 12 & 10,53 \\
S1 & 87 & 76,32 \\
S2 & 15 & 13,16 \\
\hline Jumlah & 114 & 100,00 \\
\hline
\end{tabular}

Berdasarkan data yang disajikan dalam Tabel 4.4 tampak bahwa, dari 114 orang responden penelitian ini 12 orang responden $(10,53 \%)$ memiliki jenjang studi D3; 87 orang $(76,32 \%)$ mempunyai jenjang studi $\mathrm{S} 1$; dan 15 orang $(13,16 \%)$ mempunyai jenjang studi S2. Dengan demikian dapat disimpulkan bahwa sebagian 
besar responden penelitian ini memiliki jenjang studi S1.

\section{Deskripsi Variabel Penelitian}

Deskripsi variabel penelitian ini bertujuan untuk memberikan gambaran mengenai kualitas dari masing-masing variabel penelitian. Deskripsi variabel dilakukan dengan menggunakan kategori. Hasil deskripsi terhadap masingmasing variabel penelitian ini adalah sebagai berikut.

\section{Minat Menggunakan FB untuk Pembelian Online \\ Deskripsi terhadap variabel Minat Menggunakan FB untuk Pembelian online disajikan dalam Tabel 4.6 berikut.}

Tabel 4.6.

Deskripsi Variabel Minat Menggunakan FB untuk Pembelian Online

\begin{tabular}{lcc}
\hline \multicolumn{1}{c}{ Kategori } & $\begin{array}{c}\text { Jumlah } \\
\text { (orang) }\end{array}$ & $\begin{array}{c}\text { Persentase } \\
(\%)\end{array}$ \\
\hline Sangat Rendah & 10 & 8,77 \\
Rendah & 14 & 12,28 \\
Sedang & 61 & 53,51 \\
Tinggi & 29 & 25,44 \\
Sangat Tinggi & 10 & 8,77 \\
\hline \multicolumn{1}{c}{ Jumlah } & 114 & 100,00
\end{tabular}

Sumber: Data Primer, 2018 diolah.

Berdasarkan deskripsi

variabel yang disajikan dalam Tabel 4.6 maka tampak bahwa, dari 114 orang responden penelitian ini 10 orang $(8,77 \%)$ mempunyai minat yang tergolong sangat rendah; 14 orang $(12,28 \%)$ mempunyai minat yang tergolong rendah; 61 orang $(53,51 \%)$ mempunyai minat yang tergolong sedang; 29 orang $(25,44 \%)$ mempunyai minat yang tergolong tinggi; dan 10 orang $(8,77)$ mempunyai minat yang tergolong sangat tinggi. Dengan demikian dapat disimpulkan bahwa, sebagian besar responden penelitian ini mempunyai minat menggunakan FB untuk pembelian online ang tergolong sedang.

2. Sikap terhadap Penggunaan FB

Deskripsi terhadap variabel Sikap terhadap penggunaan FB disajikan dalam Tabel 4.7 berikut. 
Tabel 4.7.

Deskripsi Variabel Sikap Terhadap Penggunaan FB

\begin{tabular}{lcc}
\hline \multicolumn{1}{c}{ Kategori } & $\begin{array}{c}\text { Jumlah } \\
(\text { orang) }\end{array}$ & $\begin{array}{c}\text { Persentase } \\
(\%)\end{array}$ \\
\hline Sangat Tidak Baik & - & - \\
Tidak Baik & - & - \\
Cukup Baik & 27 & 23,68 \\
Baik & 32 & 28,07 \\
Sangat Baik & 55 & 48,25 \\
\hline \multicolumn{1}{c}{ Jumlah } & 114 & 100,00 \\
\hline
\end{tabular}

Sumber: Data Primer, 2018 diolah.

Berdasarkan deskripsi

variabel yang disajikan dalam

Tabel 4.7 maka tampak

bahwa, dari 114 orang

responden penelitian ini 27

orang $(23,68 \%)$ mempunyai

sikap terhadap penggunaan

FB yang tergolong cukup

baik; 32 orang $(28,07 \%)$

mempunyai sikap terhadap

penggunaan FB yang tergolong baik; dan 55 orang $(48,25 \%)$ mempunyai sikap terhadap penggunaan FB yang tergolong sangat baik. Dengan demikian dapat disimpulkan bahwa sebagian besar responden penelitian ini mempunyai sikap terhadap penggunaan FB yang tergolong sangat baik.

\section{Norma-norma Subyektif}

Deskripsi terhadap variabel Norma-norma subyektif disajikan dalam Tabel 4.8 berikut.

Tabel 4.8

Deskripsi Variabel Norma-norma Subyektif

\begin{tabular}{lcc}
\hline \multicolumn{1}{c}{ Kategori } & $\begin{array}{c}\text { Jumlah } \\
\text { (orang) }\end{array}$ & $\begin{array}{c}\text { Persentase } \\
(\%)\end{array}$ \\
\hline Sangat Tidak Baik & - & - \\
Tidak Baik & - & - \\
Cukup Baik & 25 & 21,93 \\
Baik & 36 & 31,58 \\
Sangat Baik & 53 & 46,49 \\
\hline \multicolumn{1}{c}{ Jumlah } & 114 & 100,00 \\
\hline
\end{tabular}

Sumber: Data Primer, 2018 diolah.

Berdasarkan deskripsi

variabel yang disajikan dalam

Tabel 4.8 maka tampak bahwa, dari 114 orang responden penelitian ini 25 orang $(21,93 \%)$ mempunyai 
norma-norma subyektif yang tergolong cukup baik; 36 orang $(31,58 \%)$ mempunyai norma-norma subyektif yang tergolong baik; dan 53 orang $(46,49 \%)$ mempunyai normanorma subyektif yang tergolong sangat baik. Dengan demikian dapat disimpulkan bahwa sebagian besar responden penelitian ini mempunyai norma-norma subyektif yang tergolong sangat baik.

\section{Kontrol Perilaku}

Deskripsi terhadap variabel Kontrol perilaku disajikan dalam Tabel 4.9 berikut.

Tabel 4.9.

Deskripsi Variabel Kontrol Perilaku

\begin{tabular}{lcc}
\hline \multicolumn{1}{c}{ Kategori } & $\begin{array}{c}\text { Jumlah } \\
\text { (orang) }\end{array}$ & $\begin{array}{c}\text { Persentase } \\
(\%)\end{array}$ \\
\hline Sangat Tidak Baik & - & - \\
Tidak Baik & - & - \\
Cukup Baik & 21 & 18,42 \\
Baik & 36 & 31,58 \\
Sangat Baik & 57 & 50,00 \\
\hline \multicolumn{1}{c}{ Jumlah } & 114 & 100,00
\end{tabular}

Sumber: Data Primer, 2018 diolah.

Berdasarkan deskripsi variabel yang disajikan dalam Tabel 4.9 maka tampak bahwa, dari 114 orang responden penelitian ini 21 orang $(18,42 \%)$ mempunyai kontrol perilaku yang tergolong cukup baik; 36 orang $(31,58 \%)$ mempunyai kontrol perilaku yang tergolong baik; dan 57 orang $(50,00 \%)$ mempunyai kontrol perilaku yang tergolong sangat baik. Dengan demikian dapat disimpulkan bahwa sebagian besar responden penelitian ini mempunyai kontrol perilaku yang tergolong sangat baik.

\section{Kegunaan}

Deskripsi terhadap variabel Kegunaan disajikan dalam Tabel 4.10 berikut. 
Tabel 4.10.

Deskripsi Variabel Kegunaan

\begin{tabular}{llr}
\hline \multicolumn{1}{c}{ Kategori } & $\begin{array}{l}\text { Jumlah } \\
\text { (orang) }\end{array}$ & $\begin{array}{c}\text { Persentase } \\
(\%)\end{array}$ \\
\hline Sangat Tidak Berguna & - & - \\
Tidak Berguna & 6 & 5,26 \\
Cukup Berguna & 10 & 8,77 \\
Berguna & 17 & 14,91 \\
Sangat Berguna & 81 & 71,05 \\
\hline \multicolumn{1}{c}{ Jumlah } & 114 & 100,00 \\
\hline Sumber: Data Primer, 2018 diolah. & & \\
Berdasarkan deskripsi & $(14,91 \%)$ & menilai \\
variabel yang disajikan dalam & penggunaan FB berguna; dan \\
Tabel 4.10 maka tampak & 81 orang (71,05\%) menilai \\
bahwa, dari 114 orang & penggunaan FB & sangat \\
responden penelitian ini 6 & berguna. Dengan demikian \\
orang (5,26\%) menilai & dapat disimpulkan bahwa, \\
penggunaan FB tidak & sebagian besar responden \\
berguna; 10 orang (8,77\%) & menyatakan & bahwa \\
menilai penggunaan FB & penggunaan FB & sangat \\
cukup berguna, 17 orang & berguna.
\end{tabular}

\section{Kemudahan Penggunaan}

Deskripsi terhadap variabel Kemudahan penggunaan disajikan dalam Tabel 4.11 berikut.

Tabel 4.11.

Deskripsi Variabel Kemudahan Penggunaan

\begin{tabular}{lcr}
\hline \multicolumn{1}{c}{ Kategori } & $\begin{array}{c}\text { Jumlah } \\
\text { (orang) }\end{array}$ & $\begin{array}{c}\text { Persentase } \\
(\%)\end{array}$ \\
\hline Sangat Tidak Mudah & - & - \\
Tidak Mudah & 6 & 5,26 \\
Cukup Mudah & 10 & 8,77 \\
Mudah & 17 & 14,91 \\
Sangat Mudah & 81 & 71,05 \\
\hline \multicolumn{1}{c}{ Jumlah } & 114 & 100,00 \\
\hline
\end{tabular}

Sumber: Data Primer, 2018 diolah.

Berdasarkan deskripsi

variabel yang disajikan dalam Tabel 4.10 maka tampak bahwa, dari 114 orang responden penelitian ini 6 orang $(5,26 \%)$ menilai penggunaan FB tidak mudah; 10 orang $(8,77 \%)$ menilai 


$\begin{array}{llr}\text { penggunaan } & \text { FB } & \text { cukup } \\ \text { mudah, } 17 \text { orang } & (14,91 \%) \\ \text { menilai penggunaan } & \text { FB } \\ \text { mudah; dan } 81 & \text { orang } \\ (71,05 \%) & & \text { menilai } \\ \text { penggunaan } \quad F B & \text { sangat }\end{array}$

\section{Analisis Jalur (Path Analysis)}

Pengujian hipotesis penelitian ini dilakukan dengan menggunakan analisis jalur (path analysis). Analisis jalur pada dasarnya merupakan analisis terhadap beberapa model regresi secara bersamaan. Analisis jalur yang dilakukan dalam penelitian terdiri atas dua bagian, yaitu: uji asumsi kecocokan model (goodness of fit), dan analisis struktural. mudah. Dengan demikian dapat disimpulkan bahwa, sebagian besar responden menyatakan bahwa penggunaan FB sangat mudah.

1. Uji Asumsi Kecocokan Model (Goodness of Fit)

Uji asumsi kecocokan model ini bertujuan untuk menguji apakah data yang diperoleh dari penelitian cocok dengan model yang digunakan. Hasil uji asumsi kecocokan model dalam penelitian ini disajikan dalam Tabel 4.12 berikut.

Tabel 4.11.

Deskripsi Variabel Kemudahan Penggunaan

\begin{tabular}{lcc}
\hline \multicolumn{1}{c}{ Parameter } & Nilai & Syarat \\
\hline Chi Square & 2,$36 ; \mathrm{p}=0,091$ & Kecil, tidak \\
CMIgnifikan $(\mathrm{p}>0,05)$ \\
GFI & 2,000 & $\leq 2,00$ \\
AGFI & 0,994 & $\geq 0,90$ \\
TLI & 0,952 & $\geq 0,90$ \\
CFI & 0,978 & $\geq 0,95$ \\
RMSEA & 0,977 & $\geq 0,95$ \\
\hline
\end{tabular}

Sumber: Data Primer, 2018 diolah.

Berdasarkan hasil uji asumsi kecocokan model yang disajikan dalam Tabel 4.11 dapat diintepretasikan sebagai berikut:

a. Nilai chi square disyaratkan kecil dan tidak signifikan. Hasil analisis menunjukkan model memiliki nilai chi square $=2,36$ (kecil) dan tidak signifikan

$(\mathrm{p}=0,091>0,05), \quad$ berarti memenuhi syarat. Dengan demikian ditinjau dari nilai chi square model penelitian ini tergolong baik.

b. Nilai CMIN/DF disyaratkan $\leq 2,00$. Hasil analisis menunjukkan model memiliki nilai 
$\mathrm{CMIN} / \mathrm{DF}=2,000$, berarti memenuhi syarat. Dengan demikian ditinjau dari nilai CMIN/DF model penelitian ini tergolong baik.

c. Nilai GFI disyaratkan $\geq$ 0,90. Hasil analisis menunjukkan bahwa model memiliki nilai GFI=0,994, berarti memenuhi syarat. Dengan demikian ditinjau dari nilai GFI model penelitian ini tergolong baik.

d. Nilai AGFI disyaratkan $\geq$ 0,90. Hasil analisis menunjukkan bahwa model memiliki nilai AGFI=0,952, berarti memenuhi syarat. Dengan demikian ditinjau dari nilai AGFI model penelitian ini tergolong baik.

e. Nilai TLI disyaratkan $\geq$ 0,95. Hasil analisis menunjukkan bahwa model memiliki nilai TLI $=0,978, \quad$ berarti memenuhi syarat. Dengan demikian ditinjau dari nilai TLI model penelitian ini tergolong baik.

f. Nilai CFI disyaratkan $\geq$ 0,95. Hasil analisis menunjukkan bahwa model memiliki nilai $\mathrm{CFI}=0,977, \quad$ berarti memenuhi syarat. Dengan demikian ditinjau dari nilai CFI model penelitian ini tergolong baik.

g. Nilai RMSEA disyaratkan $\leq 0,08$. Hasil analisis menunjukkan bahwa model memiliki nilai RMSEA $=0,064$, berarti memenuhi syarat. Dengan demikian ditinjau dari nilai RMSEA model penelitian ini tergolong baik.

Berdasarkan hasil uji kecocokan model yang telah dilakukan, ternyata model penelitian cocok dengan data yang diperoleh, atau dengan kata lain model penelitian ini tergolong baik.

\section{F. Pembahasan}

$\begin{array}{ccr}\text { Hasil } & \text { penelitian } & \text { ini } \\ \text { menunjukkan } & \text { bahwa } & \text { minat } \\ \text { menggunakan } & \text { FB } & \text { untuk }\end{array}$ pembelian produk secara online secara langsung dipengaruhi oleh sikap, norma-norma-norma subyektif, kontrol perilaku, dan kegunaan. Sedangkan sikap dipengaruhi oleh kegunaan dan kemudahan penggunaan.

Sikap terhadap penggunaan FB berpengaruh positif dan signifikan pada minat menggunakan FB untuk pembelian online $\left(\beta_{1}=0,269 ; p=0,001\right)$. Hal ini menunjukkan bahwa, jika sikap semakin baik maka minat akan semakin meningkat. Hasil penelitian ini selaras dengan hasil penelitian yang dilakukan oleh Cameron (2012), Jabari (2012).

Norma-norma subyektif berpengaruh positif dan signifikan pada minat menggunakan FB untuk pembelian online $\left(\beta_{2}=0,202 ; p=0,019\right)$. Hal ini menunjukkan bahwa, jika normanorma subyektif semakin baik maka minat akan semakin 
meningkat. Kontrol perilaku berpengaruh positif dan signifikan pada minat menggunakan FB untuk pembelian online $\left(\beta_{3}=0,324 ; p=0,003\right)$. Hal ini menunjukkan bahwa, jika kontrol perilaku semakin baik maka minat akan semakin meningkat. Kegunaan berpengaruh positif dan signifikan pada Sikap terhadap penggunaan FB $\left(\beta_{5}=0,065 ; p=0,0041\right)$. Hal ini menunjukkan bahwa, jika kegunaan semakin baik maka minat akan semakin meningkat. Kemudahan penggunaan berpengaruh positif dan signifikan pada Sikap terhadap penggunaan FB $\left(\beta_{6}=0,339 ; p=0,000\right)$. Hal ini menunjukkan bahwa, jika kemudahan penggunaan semakin baik maka minat akan semakin meningkat.

\section{KESIMPULAN}

1. Sikap terhadap penggunaan FB berpengaruh positif dan signifikan pada minat menggunakan FB untuk pembelian online $\left(\beta_{1}=0,269 ; p=0,001\right)$.

2. Norma-norma subyektif berpengaruh positif dan signifikan pada minat menggunakan FB untuk pembelian online $\left(\beta_{2}=0,202 ; p=0,019\right)$.

3. Kontrol perilaku berpengaruh positif dan signifikan pada minat menggunakan FB untuk pembelian online $\left(\beta_{3}=0,324 ; p=0,003\right)$.

4. Kegunaan berpengaruh positif dan signifikan pada minat menggunakan FB untuk pembelian online $\left(\beta_{4}=0,343 ; p=0,000\right)$.

5. Kegunaan berpengaruh positif dan signifikan pada Sikap terhadap penggunaan FB $\left(\beta_{5}=0,065 ; \mathrm{p}=0,0041\right)$.

6. Kemudahan penggunaan berpengaruh positif dan signifikan pada Sikap terhadap penggunaan FB $\left(\beta_{6}=0,339 ; \mathrm{p}=0,000\right)$.

\section{DAFTAR PUSTAKA}

Aaker, D.A., Kumar, V., and Day, G.S. 2004. Marketing Research. Eighth Edition. New York: John Wiley \& Sons, Inc.

Amin, H. 2009. An Analysis Of Online Banking Usage Intentions: An Extension Of The Technology Acceptance Model. International Journal Business and Society, Vol. 10 No. 1, pp. 27- 40.

Azwar, S. 2007. Metode Penelitian. Yogyakarta: Pustaka Pelajar.

Azwar, S. 2008. Sikap Manusia: Teori dan Pengukurannya. Edisi Kedua, Yogyakarta: Pustaka Pelajar.

Aghdaie1, S.F.A, Sanayei, A., and Etebari, M. 2012. Evaluation of the Consumers' Trust Effect on Viral Marketing Acceptance Based on the Technology Acceptance Model. International Journal of Marketing Studies; Vol. 4, No. 6, pp. 79-94. 
Barnes, S.J., and Bohringer, M. 2011. Modeling Use Continuance Behavior In Microbloging Services : The Case Of Twitter. Journal of Computer Information Systems. Summer, pp. 1-10.

Celik, H.E., And Yilmaz, V. 2011. Extending The Technology Acceptance Model For Adoption Of E-Shopping By Consumers In Turkey. Journal of Electronic Commerce Research, Vol. 12, No. 2, pp. 152-164.

Chen, S.C, Li, S.H., And Li, C.Y. 2011. Recent Related Research In Technology Acceptance Model: A Literature Review. Australian Journal of Business and Management Research, Vol.1 No.9, pp. 124-127.

Fusilier, M. and Durlabhji, S. 2005. An Exploration Of Student Internet Use In India The Technology Acceptance Model And The Theory Of Planned Behaviour. CampusWide Information Systems, Vol. 22 No. 4, pp. 233-246.

George, J. F. 2004. The Theory of Planned Behavior and Internet Purchasing, Internet Research, Vol. 14 No. 3, pp. 198-212.

Hair, J. F.; Black, W. C.; Babin, B. J.; Anderson, R. E.; Tatham, R. L. 2006. Multivariate Data Analysis. New Jersey, Upper Saddle River, $6^{\text {th }}$, Pearson Educational International.
Jadi, B.C. 2009. Asyiknya Pakai Facebook. Yogyakarta: Moncer Publisher.

Kassem, N. O., and Lee, J. W. 2004. Understanding Soft Drink Consumption Among Male Adolescents Using Theory of Planned Behavior, Journal of Behavioral Medicine, Vol. 27 No. 3, pp. 273-295.

Kotler, P. 2005. Manajemen Pemasaran. Jakarta: PT Indeks.

Madcoms. 2011. Facebook dan Twitter untuk Pemula. Yogyakarta: Penerbit Andi Offset.

Morrisan, 2010. Manajemen Public Relation: Strategi Humas Profesional. Jakarta: Kencana Prenada Media Group.

Mowen, J. C. dan Minor, M. 2002. Perilaku Konsumen. Edisi Kelima, Jakarta: Erlangga.

Nasri, W., and Charfeddine, L. 2012. An Exploration of Facebook.Com Adoption in Tunisia Using Technology Acceptance Model (TAM) and Theory of Reasoned Action (TRA). Institute of Interdisciplinary Business Research, Vol. 4 No. 5, pp. 948-968.

Peter, J. P. dan Olson, J. C. 2000. Perilaku Konsumen dan Strategi Pemasaran. Edisi Keempat, Jakarta: Erlangga. 
Peterson, D.K. 2012. The Colbert Bump ${ }^{\circledR}$ and The Facebook ${ }^{\circledR}$ Follow-Through for Generation Snark: A Test and Extension of The Ajzen's Theory of Planned Behavior for 2012. Journal of Management Research, Vol. 4 No. 3, pp. 43-65.

Priyatno, D. 2010. Twitter untuk Pemula. Yogyakarta: Penerbit Gava Media.

San, A.N.C. and Yee, C.J. 2013. The Modified Technology Acceptance Model for Private Clinical Physicians: A Case Study in Malaysia, Penang. International Journal of Academic Research in Business and Social Sciences. Vol. 3 No. 2, pp. 380-403.

Scannell, T. V, Calantone, R.J., and Melnyk, S.A. 2012. Shop Floor Manufacturing Technology Adoption Decisions: An Application Of The Theory Of Planned Behavior. Journal of Manufacturing Technology Management. Vol. 23 No. 4, pp. 464-483.

Schiffman, L. G. dan Kanuk, L. L. 2004. Perilaku Konsumen. Edisi Ketujuh, Jakarta: Indeks.

Sekaran, U. 2003. Research Methods for Business: A Skill Building Approach. Fourth Edition, New York: John Wiley \& Sons, Inc.
Shih, Y. Y. and Fang, K. 2004. The Use of a Decomposed Theory of Planned Behavior to Study Intenet Banking in Taiwan, Internet Research, Vol. 14 No. 3, pp. 213-223.

Sheikhshoaei, F., and Oloumi, T. 2011. Applying the technology acceptance model to Iranian engineering faculty libraries. The Electronic Library, Vol. 29 No. 3, pp. 367-378.

Sugiyono. 2011. Metode Penelitian Administrasi. $\quad$ Bandung: Tarsito.

Yaghoubi, N.M, and Bahmani, E, 2010. Factors Affecting the Adoption of Online Banking An Integration of Technology Acceptance Model and Theory of Planned Behavior. International Journal of Business and Management, Vol. 5, No. 9, pp. 159-165.

Walgito, B. 2003. Psikologi Sosial: Suatu Pengantar. Yogyakarta: Andi Offset.

Wang, M. S; Chen, C. C.; Chang, S. C. and Yang, Y. H. 2007. Effect of Online Shopping Attiuteds, Subjective Norms and Control Beliefs on Online Shopping Intentions: A Test of The Theory of Planned Behavior, International Journal of Management, Vol. 24 No. 2, pp. 296-302. 